\title{
Peculiarities of Gamification in Foreign Language Teaching in the Context of Digitalization of Education
}

\author{
Guzel R. Nurieva * \\ Kazan Federal University, 420008, Kazan (Russia), 18 Kremlyovskaya street, g3006@yandex.ru
}

\begin{abstract}
The focus of the present study is the concept of gamification in educational process. The relevance of the problem at issue in the article is due to a tendency to the digitalization of education and the lack of empirical research on the implementation gamification in foreign language teaching.

The goal of this study was to confirm that foreign language teaching with the use of gamification technology is more effective than traditional ways of teaching and teaching with the use of classical gaming technologies.

This article examines the findings of a theoretical analysis of scientific literature on the concept of gamification, its elements and players' types. The paper describes the difference between gamification and such concepts as play, game, simulation, serious games. An empirical research is based on the pedagogical experiment, the results show that the use of gamification in foreign language teaching makes it possible to improve the language competencies of the students. Meanwhile, it is noted that the implementation of gamification in the educational process requires a complex approach: this requires understanding of the students' player types, developing of game application, controlling of gamification implementation into the traditional forms of teaching at all the stages.
\end{abstract}

Keywords: gamification, digitalization, foreign language teaching, education.

\section{(C) 2020 Guzel R. Nurieva}

This is an open access article distributed under the terms of the Creative Commons Attribution License (CC BY 4.0), which permits unrestricted use, distribution, and reproduction in any medium, provided the original author and source are credited.

Published by Kazan federal university and peer-reviewed under responsibility of IFTE-2020 (VI

International Forum on Teacher Education)

\footnotetext{
*Corresponding author. E-mail: g3006@yandex.ru
} 


\section{Introduction}

The modern world is becoming more and more digital. New technologies and innovations are being implemented in virtually all spheres of human activity. It is impossible to ignore the processes of computerization and digitalization in society, as well as to ignore the use of digital technologies in educational process. A national project «Modern digital educational environment in Russian Federation» (Ministry of education of the Russian Federation, 2019) and the program «Digital economy of the Russian Federation» (Ministry of Digital Development, Communications and Mass Media of the Russian Federation, 2019), adopted at a government level, have directed educational organizations to gradual transfer of educational environment to digital format. New national project «Education» (Ministry of Education of the Russian Federation, 2019) deserves particular attention too. It was approved at the end of presidium of the Council of the President of the Russian Federation for strategic development and national project on the $24^{\text {th }}$ of December and issued on the website of Russian Government in February 2019. There are ten federal projects in present national project; one of them is «Digital educational environment» (Ministry of education of the Russian Federation, 2019). Its purpose is to develop a modern and safe digital educational environment, to provide availability and high quality of education. Federal information and service platform «Digital educational environment» should be established until the $31^{\text {st }}$ of December 2024 . It will contain educational content, information solutions and provide integration with relevant regional information resources.

Transfer of education to digital format has directed educational organizations to change the education process too. One of the most relevant areas of educational technologies development is gamification. In the scientific literature researchers define gamification as the usage of game methods in non-game context (Varenina, 2014; Goryachkina, Kudryavtseva \& Balina, 2016). However, the usage of game elements is not the innovation for educational organizations. In Russian pedagogy the issue of gaming activities was developed by Ushinsky (1968), Elkonin (2005), Rubinshtein (1989). They investigated game peculiarities in the educational process and upbringing. Gaming technology is highly effective, universal and suitable for all educational purposes method (Igna, 2011). In High School even before the occurrence of the phenomenon gamification game techniques and methods were widely used in teaching.

This leads us to think that the phenomenon of games is not relevant for pedagogical researches. However, the growth of Generation $\mathrm{Z}$ leads us to take a new look at the function of games in the educational activity. Generation $\mathrm{Z}$ is the term used in the world for human generations born approximately in 2000-2019 years. It corresponds to a theory of generation invented by Neil Howe and William Strauss (2000). Representatives of this generation actively use tablets, gadgets, smart watches. This is the first digital 
generation, and its representatives are called «Digital Natives» (Prensky, 2010). No doubt that the appearance of digital generation has an impact on the aims, context and tools of pedagogical process. Along with changes in pedagogical process methods of teaching are changing too. So, the use of game elements as the one of the methods in foreign language teaching also has changed. Today it is considered as gamification. In spite of the fact that gamification can also represent traditional game mechanics, nevertheless it is considered as a part of digital education.

The concept of gamification is widely examined in the writings of Russian and foreign researches (Lobacheva, 2018; Nechunaev, 2018; Stepashkina, 2017; Herger, 2014; Werbach, 2020). So, Herger (2014) makes a clear distinction between gamification and play, game, simulation and serious games. In spite of similarity of these concepts they are different. According to Herger (2014), there are neither rules, nor goals in play. The main thing is activity itself. Games on the contrary have both rules and goals. For example, they help to solve a definite problem, but games don't have a direct real-world outcome too. Serious games are games created for a primary goal other than fun and entertainment. They possess all game elements, but their aim is to achieve something that is predetermined. Serious games have serious background and purposes, for example training pilots. Simulations look like serious games; however, they simulate real life. Its objective is user training in an environment similar to real life. According to MerriamWebster's Dictionary simulation is defined as something that is made to behave like something else so it can be used to train people (Staff, 2004). Gamification is the usage of game elements and game mechanics in non-game contexts, its goal is to engage users and solve particular problems (Herger, 2014). Comparing all definitions, he created this matrix (Table 1). The comparative parameters are the following: spontaneity, the existence of rules and goals, inner structure, real world/ gaming space and system. 


\section{Table 1.}

\section{Matrix of comparison}

\begin{tabular}{|c|c|c|c|c|c|}
\hline & Play & Game & Serious & Simulation & Gamification \\
\hline Spontaneous & + & - & - & - & $-/+$ \\
\hline Rules & - & + & + & + & + \\
\hline Goals & - & + & + & + & + \\
\hline Structured & - & + & + & + & + \\
\hline Real-world & - & - & $-/+$ & $-/+$ & + \\
\hline In-System & - & - & - & & + \\
\hline
\end{tabular}

The table shows that gamification crosses "game" in such positions as existence of rules, goals and the game's structure. However, the game shifts the player location to the gaming space, whereas the gamification leaves us in the real world, it means that the participant remains himself, takes on no roles and moves only from his own motivation and inner goal, for instance to learn English language. Gamified educational process should be structured because teaching program needs to be divided into certain stages, and every stage should have own goal, working for the general purpose of the course. Simulation is more similar to gamification. It creates an illusion of reality on the computer environment and serves the training purposes. In comparison with the simulation gamification creates an illusion of the game and uses the mechanics of the computer environment in the real world. With regard to the system parameter, gamified educational process doesn't mean the usage of separate game elements but the whole process of gamified maintenance of educational activity. Gamification fully accompanies educational course - from goals and purposes setting to final control of knowledge.

In implementing gamification into the foreign language teaching it is necessary to know what player types the students are. The game researcher Richard Bartle (2004) divided player personalities into four types: 
killers, achievers, socializers and explorers. Killers are players whose main goal is to win over the other players, they want to fight with the others. They are really competitive. The main purpose for achievers is to earn points, levels and virtual goods. Prestige of having these items is a motivation for achieves, even if these rewards don't help them to achieve game success. Explorers like discovering the virtual world. They try to find every hidden corner or feature in the virtual world. For socializers game itself is not so important, they play games to communicate with other people and users. Each of students (and all people in general) contains these four players' characteristics. Some characteristics predominate, but they can change with the situation. Awareness and understanding of students' player types will help to implement gamification into the foreign language teaching more effectively, that, in turn, will lead to a better knowledge acquisition.

According to Werbach (Werbach, 2020), gamification contains game elements, game design techniques and non-game context. There are three parts to this definition.

Game elements can be divided into game mechanics and game dynamics. The game mechanics are the foundation for gamification in education. They are used to gamify any process or content. There are following game mechanics: scores, levels, badges and trophies, leaderboards, tasks, avatars and individual profile.

Scores, points are among the prime motivator, collecting them make the student feel rewarded. Collected scores and points unlock new levels for the students. There is no punishment for failure, only rewards for the efforts.

Levels are the common mechanics in the games. Starting from the simple tasks and slowly increasing the level of difficulty. The increase in difficulty as well as progressing to new level gives students a development, and thus improving their competence. The examples of language learning platforms that use levels are DuoLingo, Lingualeo. As the student progresses, he unlocks new levels.

Badges and trophies are symbols of student's status. They can be awarded to the student for his achievements.

As for the game dynamics, they can drive the student motivation and need to avoid making the game monotonous. They are Achievements, Competition, Progress, Collaboration, and Surprise. Competition is one of the prime motivations that make students to move forward and do their best. 
Game elements are investigated and described in the writings of such researchers as Deterding et al. (2011), Brigham (2015), Amory et al. (1999).

As for game design techniques, it is considered to be the visual experience of the game.

Non-game context is everything where objective is behind the game, where the purpose is other than playing the game.

Gamification brings game technics to the teaching system without turning it into a game. Its elements can easily be implemented into the educational process that will certainly help to significantly increase students' motivation to learning.

\section{Purpose and objectives of the study}

The goal of this study is to confirm that foreign language teaching with the use of gamification technology is more effective than traditional ways of teaching and teaching with the use of classical gaming technologies.

\section{Methodology}

The research based on the theoretical and empirical methods: analysis of studies on gamification in education; Bartle's test (2004); observation, pilot modeling of pedagogical activity with the help of gamification.

\section{Experimental research base}

Experimental research was carried out in the Kazan (Volga region) Federal University on the basis of the Institute of Management, Economics and Finance. The total number of participants in the pedagogical experiment was 86 students ( 25 students in the experimental group, 30 students in the control group 1, and 31 students in the control group 2).

The study included four stages. At the first stage the analysis of the theoretical and methodological approaches was carried out, the objective and methods were singled out, the plan of present research was made.

At the second stage, educational process was organized in three variants: in the first control group (CG 1) traditional methods and teaching tools were used. In the second control group (CG 2) the lesson was 
carried out with the use of traditional game tools. In the experimental group (EG) the gamification was implemented into the educational process.

The main teaching methods in the first control group were explaining of new materials, work on a textbook, discussions, doing exercises. In the second control group traditional teaching methods were combined with the game techniques, such as widespread games Hangman, Hot seat, Mime game and others.

Before implementing gamification into the educational process of the experimental group we ran R. Bartle's test (2004) in advance to determine what type of the player every student is. Game applications were selected and implemented into the educational process in accordance with the type of the player.

At the third stage, we examined learning skills of the students, for this purpose written test was developed.

At the fourth stage of our research, received statistical data and practical results were analyzed and summarized.

\section{Results}

At the diagnostic stage of the research R. Bartle's test (2004) was run on the students of the experimental group. The test revealed the following percentage of players types (Figure 1).

\section{Figure 1}

Types of the players among the students in the experimental group

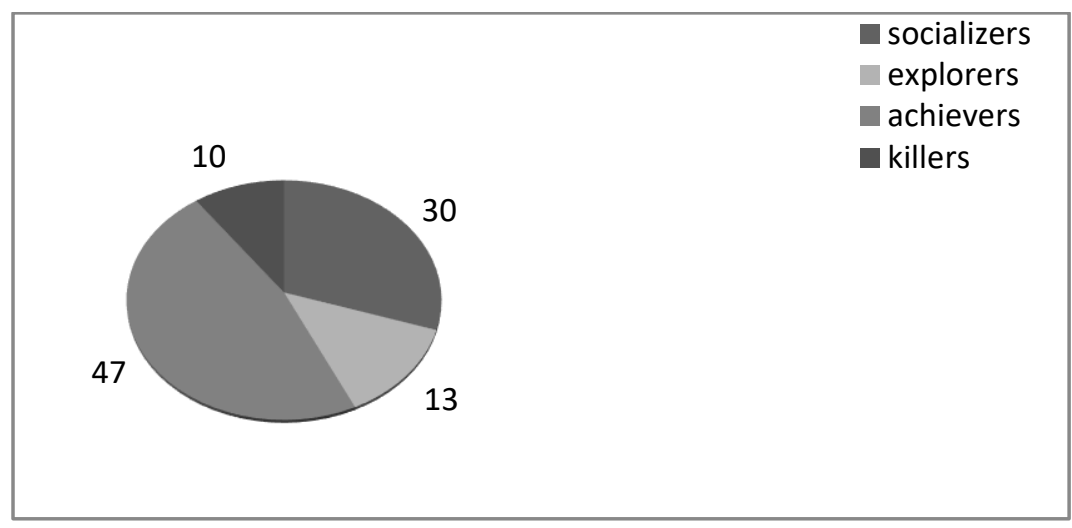


The figure 1 shows that the «achievers» are prevailed in the experimental group. Achievers are all about points and status. They like collecting badges and put them on display. They want to show their friends how they are progressing. We selected the game application taking into account the most relevant and attractive factors for the achievers. It is a popular educational online platform Lingualeo, which is offering English language learning service based on gamification methods. Lingualeo has levels, points, virtual goods which are so important for the achievers. This game application was successfully implemented into the educational process.

At the next stage of pedagogical experiment we examined acquired English language skills of the students. The results are shown below (Figure 2).

\section{Figure 2}

Indicators of students' knowledge level

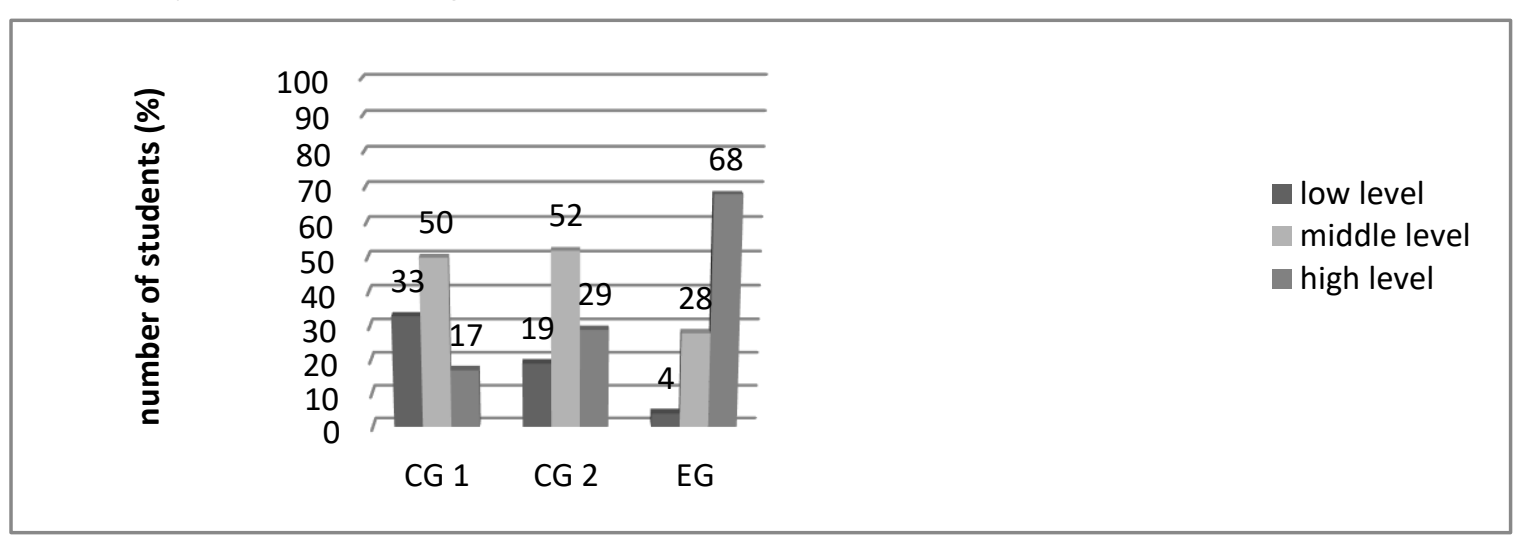

According to the figure 2 analysis of the data received reveals that both the second control group and the experimental group showed a high level of gained learning skills in comparison with the first control group. It leads us to conclude that the use of game mechanisms in foreign language teaching can improve students' language competency. The experimental group showed the best results, there gamification was implemented into the educational process.

Furthermore, we decided to analyze such a parameter as residual knowledge that means maintaining of skills and language competency for a long time. For this purpose we again examined gained language skills of the students in one month. On the basis of its results we figured out grade point average of each group, and then we compared it with grade point average of the written test which was conducted immediately after the study (Figure 3). 


\section{Figure 3}

Results of the test of the residual language skills

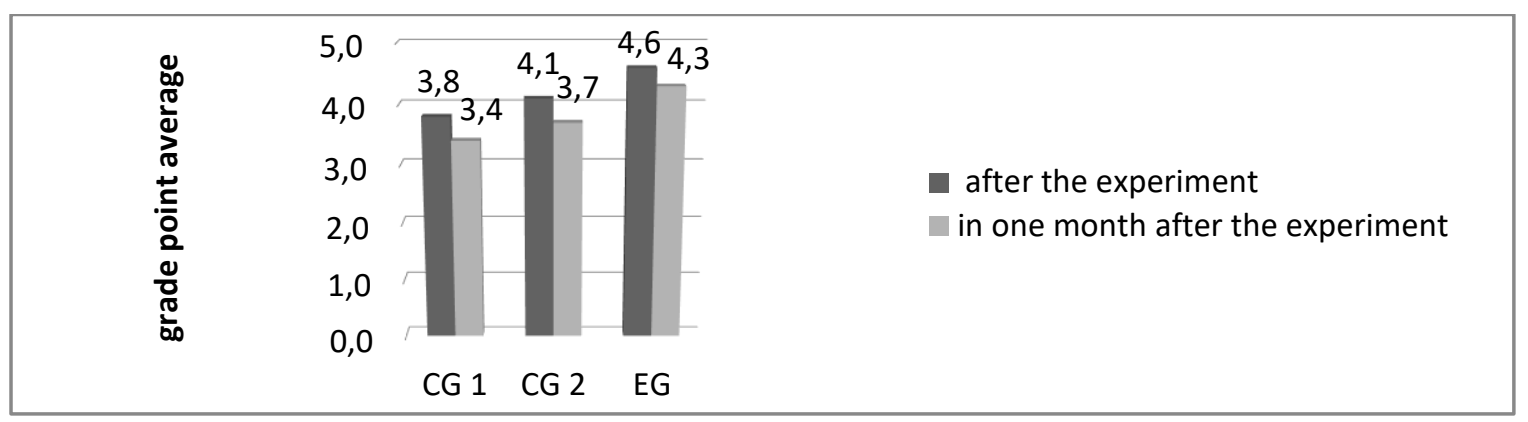

The figure 3 shows that the results of retesting slightly declined, however, the highest point belongs to the experimental group. It indicates that gamification contributes to the more effective memorizing of the studied material. To identify more significant differences in residual knowledge it is necessary to examine the students in one year after the experiment.

While the implementing gamification into the educational process of the experimental group and further its use on the English language lessons for a long time we found the following tendency: the use of gamification leads to the growing needs of students for interactive digital methods in foreign language teaching, and similar to computer games we can identify it as "gamification addiction". Therefore, in the absence of gamification students lose interest in language learning, they are demotivated to study.

Thus, despite the complexity of implementing gamification into the educational process (i.e. identifying of players' types, selecting/ developing of game program, integrating the game to the lesson, controlling all stages of gamified lesson), gamified educational process efficiency is higher than traditional teaching methods.

\section{Discussions}

Despite the obvious potential of gamification in the educational process, review of the existing theoretical literature showed that today there is a lack of an appropriate teaching strategy and methodologies for implementing gamification into the learning process. Hence, there is a need for further study of the problem of implementing gamification in education, i.e. didactic, methodological and psychological aspects of its implementing into the foreign language teaching should be developed. 
The issue of selecting/ developing of game program to pursue definite pedagogical objective is very important too; while there are many teaching digital game applications and programs, there is no unified classification of them.

\section{Conclusion}

The process of digitalization influences and will continue to influence the system of professional education in high school. Under the impact of new technologies the educational process is increasingly transforming. As a new method of foreign language teaching, gamification has a great pedagogical potential. Its role in the educational discourse, in particular with regard to the developing students' language competency, is beyond doubt. Based on the results of this research, we can say that implementing the gamification into the foreign language teaching leads to achieving certain learning objectives and as a result to improving students' language competency. However, it requires a complex and comprehensive approach: it is necessary to select/ develop a specific game program, to identify players' types, to control all stages of implementing gamification into the traditional educational process.

\section{Conflict of interest}

The authors declare that there is no conflict of interest in this report. The study was carried out without funding from any institution.

The data collected and used in this research are available and can be accessed via e-mail to g3006@yandex.ru.

\section{References}

Abitov, R. (2017). Duolingo e-learning platform as means to intensify foreign language teaching at technical universities. Education \& Self Development, 12(1), 45-55. Available at: https://doi.org/10.26907/esd12.1.04.

Amory, A., Naicker, K., Vincent, J., \& Adams, C. (1999). The use of computer games as an educational tool: identification of appropriate game types and game elements. British Journal of Educational Technology, 30(4), 311-321.

Bartle, R. A. (2004). Designing virtual worlds. The United States of America: New Riders. 
Brigham, T. J. (2015). An introduction to gamification: adding game elements for engagement. Medical reference services quarterly, 34(4), 471-480.

Deterding, S., Dixon, D., Khaled, R., \& Nacke, L. (2011). From game design elements to gamefulness: defining "gamification". In Proceedings of the 15th international academic MindTrek conference: Envisioning future media environments, 9-15.

Elkonin, D. (2005). The psychology of play. Journal of Russian \& East European Psychology, 43(1), 1121.

Goryachkina, I., Kudryavtseva, O., \& Balina, O. (2016). Gamification as a strategy of training a future specialist. National Research Tomsk State University, 2(2), 30-31.

Herger, M. (2014). Enterprise Gamification. CreateSpace Independent Publishing Platform: EGC Mesia. Retrieved from https://ru.scribd.com/document/319543577/Mario-Herger-Enterprise-GamificationEngaging-People-by-Letting-Them-Have-Fun-CreateSpace-Independent-Publishing-Platform-2014.

Howe, N., \& Strauss, W. (2000). Millennials Rising: The Next Great Generation. New York: Vintage Books.

Igna, O. (2011). The imitation (modeling) technology in professional methodical training of a foreign language teacher. Tomsk State Pedagogical University Bulletin, 9(11), 186-190.

Lobacheva, N. (2018). The concept of gaming and its role in the educational discourse. Bulletin Of The Moscow State Regional University (Pedagogics), (2), 32-42. Available at: https://doi.org/10.18384/2310-7219-2018-2-32-42.

Ministry of Digital Development, Communications and Mass Media of the Russian Federation, June 4, 2019, https://digital.gov.ru/ru/activity/directions/858/.

Ministry of Education of the Russian Federation, January 1, 2019, https://edu.gov.ru/national-project/.

Nechunaev, V. (2018). Overcoming clip thinking in contemporary students. Reflexio, 11(2), 181-207. Available at: https://doi.org/10.25205/2658-4506-2018-11-2-181-207.

Prensky, M. (2010). Digital Natives, Digital Immigrants. On the Horizon, 9(5), 1-6. 
Rubinshtein, S., Abdul'khanova-Slavskaia, K., \& Brushlinskii, A. (1989). Osnovy obshchě psikhologii. Pedagokika.

Staff, M. W. (2004). Merriam-Webster's collegiate dictionary. Springfield, Massachusetts, U.S.A.: Merriam-Webster.

Stepashkina, V. (2017). Gaming as a technology in professional activity modeling. Education \& Self Development, 12(4), 35-43. Available at: https://doi.org/10.26907/esd12.4.05.

Ushinsky, K. (1968). Selected pedagogical works. Moscow: Pedagogics.

Varenina, L. (2014). Gamification in education. Historical and social educational ideas, 6(6), 314-317.

Werbach, K. (2020). Gamification | Coursera. Coursera. Retrieved from https://www.coursera.org/learn/gamification\#about. 